\title{
Coordinated signals from the DNA repair enzymes PARP-1 and PARP-2 promotes B-cell development and function
}

\author{
Miguel A. Galindo-Campos ${ }^{1}$ - Marie Bedora-Faure ${ }^{2}$ Jordi Farrés ${ }^{1} \cdot$ Chloé Lescale $^{2} \cdot$ Lucia Moreno-Lama $^{1}$. \\ Carlos Martínez $\mathbb{D}^{3}$. Juan Martín-Caballero ${ }^{4}$. Coral Ampurdanés ${ }^{1} \cdot$ Pedro Aparicio $^{5}$ • Françoise Dantzer ${ }^{6}$. \\ Andrea Cerutti ${ }^{7,8} \cdot$ Ludovic Deriano $\mathbb{D}^{2} \cdot$ José Yélamos ${ }^{1,9}$
}

Received: 27 September 2018 / Revised: 22 March 2019 / Accepted: 25 March 2019 / Published online: 17 April 2019

(c) ADMC Associazione Differenziamento e Morte Cellulare 2019

\begin{abstract}
Poly (ADP-ribose) polymerase (PARP)-1 and PARP-2 regulate the function of various DNA-interacting proteins by transferring ADP-ribose emerging from catalytic cleavage of cellular $\beta-\mathrm{NAD}^{+}$. Hence, mice lacking PARP-1 or PARP-2 show DNA perturbations ranging from altered DNA integrity to impaired DNA repair. These effects stem from the central role that PARP-1 and PARP-2 have on the cellular response to DNA damage. Failure to mount a proper response culminates in cell death. Accordingly, PARP inhibitors are emerging as promising drugs in cancer therapy. However, the full impact of these inhibitors on immunity, including B-cell antibody production, remains elusive. Given that mice carrying dual PARP-1 and PARP-2 deficiency develop early embryonic lethality, we crossed PARP-1-deficient mice with mice carrying a B-cell-conditional PARP-2 gene deletion. We found that the resulting dually PARP-1 and PARP-2-deficient mice had perturbed bone-marrow B-cell development as well as profound peripheral depletion of transitional and follicular but not marginal zone B-cells. Of note, bonemarrow B-cell progenitors and peripheral mature B-cells were conserved in mice carrying either PARP-1 or PARP-2 deficiency. In dually PARP-1 and PARP-2-deficient mice, B-cell lymphopenia was associated with increased DNA damage and accentuated death in actively proliferating B-cells. Moreover, dual PARP-1 and PARP-2 deficiency impaired antibody responses to Tindependent carbohydrate but not to T-dependent protein antigens. Notwithstanding the pivotal role of PARP-1 and PARP-2 in DNA repair, combined PARP-1 and PARP-2 deficiency did not perturb the DNA-editing processes required for the generation of a protective antibody repertoire, including $\mathrm{Ig} \mathrm{V}(\mathrm{D}) \mathrm{J}$ gene recombination and $\operatorname{IgM}$-to-IgG class switching. These findings provide key information as to the potential impact of PARP inhibitors on humoral immunity, which will facilitate the development of safer PARP-targeting regimens against cancer.
\end{abstract}

These authors contributed equally: Ludovic Deriano, José Yélamos

Edited by A. Villunger

Supplementary information The online version of this article (https:// doi.org/10.1038/s41418-019-0326-5) contains supplementary material, which is available to authorized users.

Ludovic Deriano

ludovic.deriano@pasteur.fr

$\triangle$ José Yélamos

jyelamos@imim.es

1 Cancer Research Program, Hospital del Mar Medical Research Institute (IMIM), Barcelona, Spain

2 Genome Integrity, Immunity and Cancer Unit, Equipe Labellisée Ligue Contre le Cancer, Department of Immunology, Department of Genomes and Genetics, Institut Pasteur, 75015 Paris, France

3 Experimental Pathology Unit, IMIB-LAIB-Arrixaca, Murcia, Spain

\section{Introduction}

B-cell development is a highly regulated process that involves bone-marrow differentiation of pluripotent

4 Barcelona Biomedical Research Park (PRBB), Barcelona, Spain

5 Department of Biochemistry, Molecular Biology and Immunology, University of Murcia, Murcia, Spain

6 Biotechnology and Cell Signaling, UMR7242-CNRS, Laboratory of Excellence Medalis, ESBS, Illkirch, France

7 Catalan Institute for Research and Advanced Studies (ICREA), Barcelona, Spain

8 Inflammatory and Cardiovascular Disorders Research Program, Hospital del Mar Medical Research Institute (IMIM), Barcelona, Spain

9 Department of Immunology, Hospital del Mar, Barcelona, Spain 
hematopoietic stem-cells into pro-B-cells. These early recombination-activating gene (RAG)-positive B-cell precursors sequentially undergo RAG-dependent immunoglobulin (Ig) heavy-chain gene rearrangements to assemble a $\mathrm{V}_{\mathrm{H}} \mathrm{DJ}_{\mathrm{H}}-\mathrm{C} \mu$ protein that associates with $\mathrm{Vpre}-\mathrm{B}$ and $\lambda 5$ surrogate light chain proteins to form a pre-BCR complex. Signaling through the pre-BCR stimulates the progression of RAG-negative pre-B-cells into RAG-positive immature B-cells that undergo RAG-dependent Ig light chain $V_{L} J_{L}$ gene rearrangement. Subsequent association of $\mathrm{V}_{\mathrm{L}} \mathrm{J}_{\mathrm{L}}$ with $\mathrm{V}_{\mathrm{H}} \mathrm{DJ} \mathrm{J}_{\mathrm{H}}-\mathrm{C} \mu$ generates fully functional membranebound IgM receptors in immature B-cells, which further differentiate into transitional B-cells that progressively coexpress IgM and $\operatorname{IgD}$ receptors [1]. These transitional Bcells migrate to peripheral secondary lymphoid organs, where they further progress into mature marginal zone (MZ) or follicular (FO) B-cells [1]. This fate decision requires specific signals from B-cell-receptor and NOTCH-receptor among other signaling pathways [2, 3]. Upon antigen exposure, mature B-cells become activated and enter $\mathrm{Bcl}-6^{-}$ extrafollicular or $\mathrm{Bcl}^{-} 6^{+}$germinal center differentiation programs that lead to the formation of short-lived antibodysecreting plasmablasts or long-lived memory B-cells and antibody-secreting plasma cells, respectively [4-6].

Poly(ADP-ribose)polymerase (PARP)-1 and PARP-2 belong to a family of enzymes that cleave $\beta-\mathrm{NAD}^{+}$to transfer ADP-ribose moiety onto residues of proteins [7, 8]. Mice lacking either PARP-1 or PARP-2 show alterations of DNA integrity and repair, which supports the notion that these enzymes share functional properties that are pivotal to DNA repair [9]. Accordingly, combined PARP-1 and PARP-2 deficiency is embryonically lethal [10], which is likely due to their central role in the DNA damage response (DDR) [7, 9]. Remarkably, PARP-1 and PARP-2 deploy additional functions beyond DDR, including gene transcription, angiogenesis, and cell death [9]. In all these processes, PARP-1 and PARP-2 target distinct acceptor proteins, suggesting that these enzymes have discrete biological roles [11, 12]. For instance, PARP-2 but not PARP-1 regulates hematopoiesis [13, 14], spermatogenesis [15], and T-cell development [16, 17]. More recently, we elucidated a coordinated role of PARP-1 and PARP-2 in T-cell homeostasis [18].

In contrast, the function of PARP-1 and PARP-2 in Bcells remains elusive. Importantly, the mature B-cell compartment appears conserved in peripheral lymphoid organs from either PARP-1 or PARP-2-deficient mice [17, 18]. Given the key role of PARP-1 or PARP-2 in DNA repair, these enzymes could regulate DNA-editing processes implicated in the generation of antibody diversity. Yet, the role of PARP-1 or PARP-2 in Ig V(D)J gene recombination remains unclear or unknown [19-21]. Moreover, neither PARP-1 nor PARP-2 seems required for class-switch DNA recombination (CSR) [22].
Here, we bypassed the early embryonic lethality of dually PARP-1 and PARP-2-deficient mice [10] by crossing PARP-1-deficient mice with Cd19-cre mice carrying a B-cell-conditional PARP-2 deletion. We found that combined but not individual PARP-1 and PARP-2 deficiency impaired B-cell development and function, including antibody responses to T-independent (TI) antigens but not T-dependent (TD) antigens. Despite the crucial role of PARP-1 and PARP-2 in DDR, PARP-1 and PARP-2 were dispensable for both Ig V(D)J gene recombination and Ig CSR. By elucidating the role of PARP-1 and PARP-2 in B-cells, our findings provide essential information that may impact for the development of PARP-centered therapies.

\section{Results}

\section{Generation of PARP-1-deficient mice with B-cell- specific PARP-2 deletion}

To study the function of PARP-1 and PARP-2 in B-cells, we crossed mice harboring the floxed Parp-2-allele (Parp$\left.2^{\text {fff }}\right)$ [18] with mice expressing the Cre-recombinase under the control of the Cd19-promoter (Cd19-cre $\left.{ }^{\text {tg/tg }}\right)$ [23]. The resulting Cd19-cre ${ }^{\text {tg/+ }}$ Parp- $2^{f /+}$ mice were crossed with Parp $-1^{-/-}$mice to generate heterozygous mice that were backcrossed to give all possible combinations of targeted alleles. Only mice with Cd19-cre in heterozygosis were used in these studies. To check the efficiency of Cremediated PARP-2 deletion in Cd19 expressing B-cells, the floxed allele was PCR amplified from FACSorted bonemarrow and spleen cell subsets. Loss of the floxed allele started in $\mathrm{CD}_{4} 3^{+} \mathrm{B} 220^{+} \mathrm{IgM}^{-}$(fraction $\mathrm{A}-\mathrm{C}^{\prime}$ ) bone-marrow cells and was complete in later development stages (Fig. 1a). Indeed, a complete loss of the floxed allele takes place at pre-BII stage (Fig. 1b). Similarly, loss of the floxed allele was observed in splenic B but not T cells (Fig. 1c).

We also analyzed PARP-1 and PARP-2 protein expression in FACSorted splenic $\mathrm{B}$ and $\mathrm{T}$ cells from control (Cd19-creParp- $2^{+/+}$Parp- $1^{+/+}$), single PARP-1-deficient (Cd19-creParp- $2^{+/+}$Parp- $\mathrm{I}^{-/-}$), single PARP-2-deficient (Cd19-creParp- $2^{f f}$ Parp $\left.-1^{+/+}\right)$, and dually PARP-1 and PARP-2-deficient (CD19-creParp-2fff Parp- $\left.1^{-/-}\right)$mice. We found loss of PARP-2 in B-cells but not T cells from Cd19creParp-2 $2^{\text {fff }}$ mice (Fig. 1d). Upon in vitro activation with LPS, PARP activity was only slightly reduced in single PARP-2-deficient B-cells compared to controls, whereas a stronger reduction was observed in dually PARP-1 and PARP-2-deficient B-cells. PARP activity was sharply reduced in PARP-1-deficient B-cells but to a lesser extent than in dually PARP-1 and PARP-2-deficient B-cells (Fig. 1e). Thus, our strategy efficiently generated mice 
A

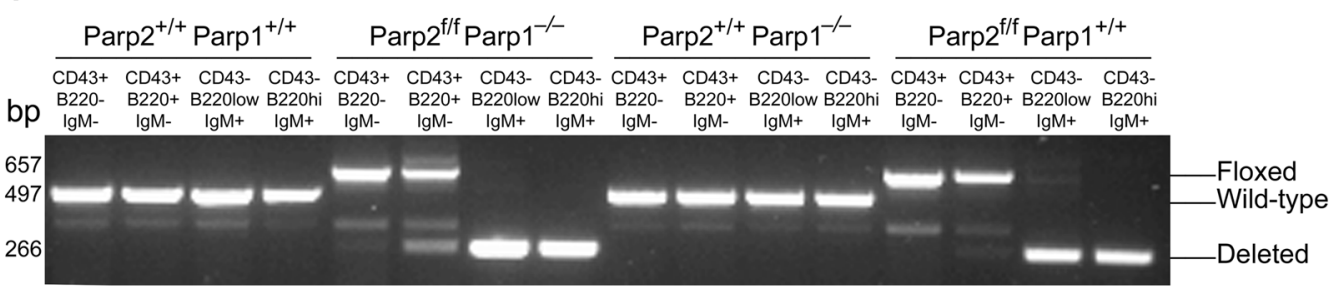

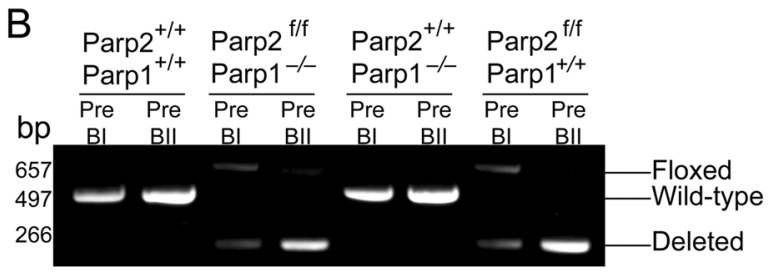

D
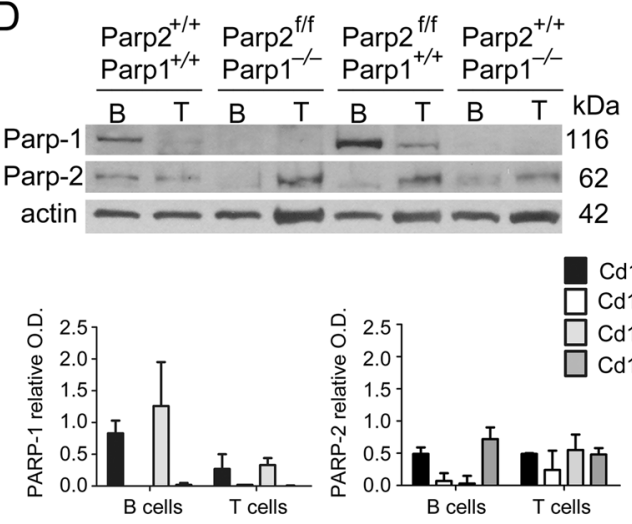

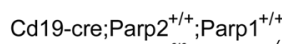
Cd19-cre:Parp2 $2^{\mathrm{f} / \mathrm{f}} ; \mathrm{Parp1}^{-1}$ Cd19-cre;Parp2 $2^{\mathrm{fff}} ; \mathrm{Parp1}^{+/+}$ Cd19-cre;Parp2 ${ }^{+/+} ;$Parp1 $^{-/}$

C

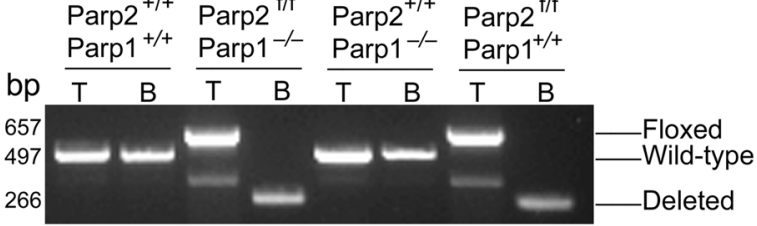

$E$

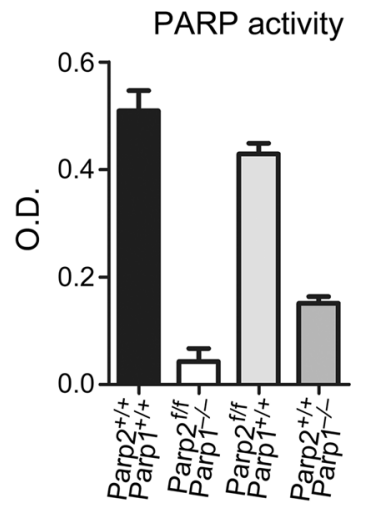

Fig. 1 Effectiveness of PARP-2 deletion in Cd19-cre;Parp-2 $2^{\mathrm{f} / \mathrm{f}}$ mice. $\mathbf{a}-$ c PCR analysis from genomic DNA in sorted bone-marrow $(\mathbf{a}, \mathbf{b})$ and splenic (c) B-cell subsets from mice of the indicated genotypes. Pre-BI cells $\left(\mathrm{B} 220^{+} \mathrm{CD}_{19}^{+} \mathrm{IgM}^{-} \mathrm{CD} 25^{-} \mathrm{CD}_{117^{+}}\right)$; Pre-BII cells $\left(\mathrm{B} 220^{+}\right.$ $\left.\mathrm{CD} 19^{+} \operatorname{IgM} \mathrm{CD}^{-} 5^{+} \mathrm{CD} 117^{-}\right) ; \mathrm{T}$ cells $\left(\mathrm{CD}^{+}\right) ;$B-cells $\left(\mathrm{B} 220^{+}\right)$ d western-blot analysis of PARP-1 and PARP-2 proteins expression in splenic $\mathrm{B}$ and $\mathrm{T}$ cells from mice of the indicated genotypes. Expression of $\beta$-actin was used as a loading control. Densitometry analysis

with combined global PARP-1 deficiency and B-cellspecific PARP-2 deficiency.

\section{PARP-1 and PARP-2 are required for normal B-cell development}

To determine the effects of PARP-1 and PARP-2 in B-cell development, we compared bone-marrow B-cells from single or dually PARP-1 and PARP-2-deficient mice as well as control mice. Bone-marrow $\mathrm{B} 220^{+}$B-cells were decreased in dually PARP-1 and PARP-2-deficient mice compared with single PARP-1-deficient, single PARP-2deficient or control mice (Fig. 2a, b). Further analysis of bone-marrow B-cell progenitors revealed that whilst fraction $\mathrm{A}-\mathrm{C}^{\prime}$ was similar in all groups, the number of B-cell progenitors from later development stages (fractions D, E, and F) was significantly decreased in dually PARP-1 and

(optical density) of PARP-1 and PARP-2 bands from western blotting is shown. The results are expressed as mean \pm SEM using samples from two different mice of each genotypes. e PARP activity in protein extracts from B-cells upon activation with LPS. Resting B-cells were isolated from spleen, cultured in the presence of LPS $(10 \mu \mathrm{g} / \mathrm{ml})$ for 2.5 days, lysed and PARP activity determined in protein extracts. Results represent the mean \pm SEM of three independent experiments carried out in triplicate

PARP-2-deficient mice compared to single PARP-1-deficient, single PARP-2-deficient or control mice (Fig. 2a, b). To evaluate how dual PARP-1 and PARP-2 deficiency affects bone-marrow cell kinetics, we analyzed BrdUlabeling rates. All bone-marrow cell subsets displayed comparable proportional BrdU-labeling in dual or single PARP-1 and PARP-2-deficient mice or controls (Fig. 2c and Table S1). However, dually PARP-1 and PARP-2-deficient mice elicited a decrease in fractions $\mathrm{D}$ and $\mathrm{E}$ production compared to single PARP-1 and PARP-2-deficient mice or controls (Fig. 2c and Table S1).

Dual PARP-1 and PARP-2 deficiency also led to a significant decrease in lymph nodes (Fig. S1) and splenic Bcells compared to single PARP-1-deficient, single PARP-2deficient or control mice (Fig. 2d, e). This reduction was due to depletion of transitional and FO B-cells, whereas MZ B-cells were numerically conserved (Fig. 2d, e) despite loss 
A

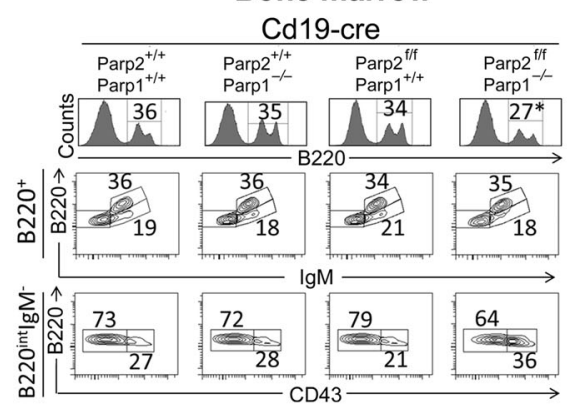

D

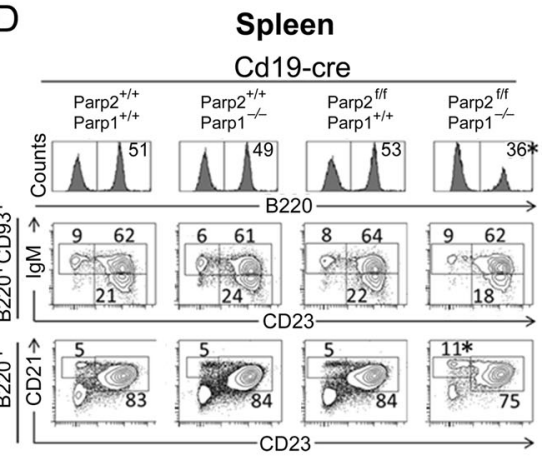

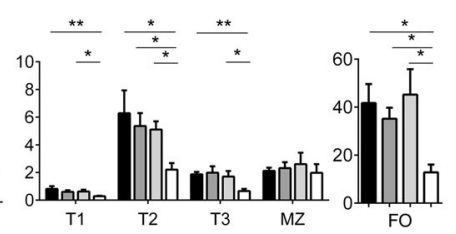
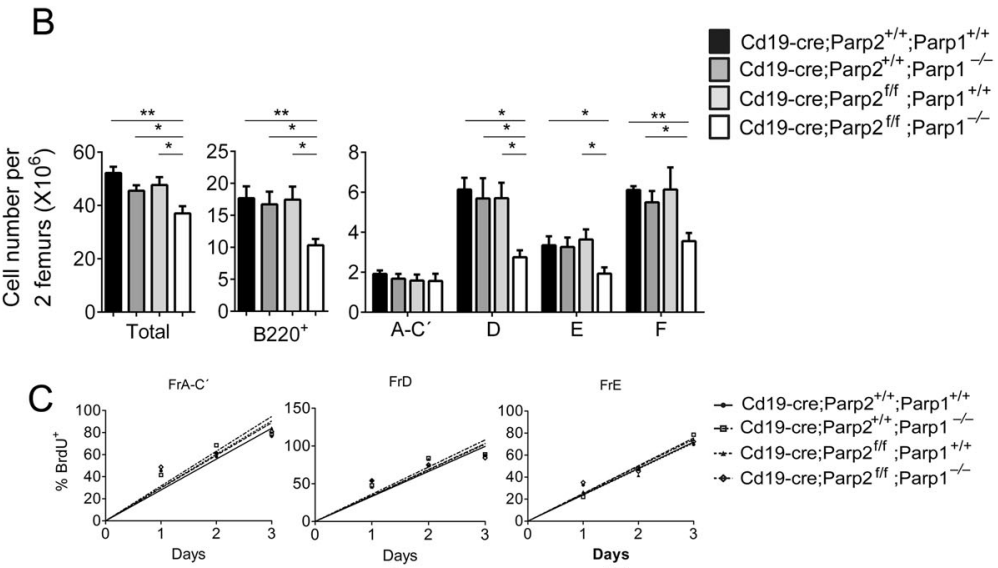

FrA-C.
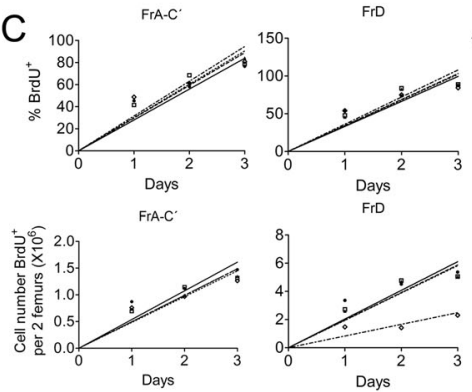

Days
FrD
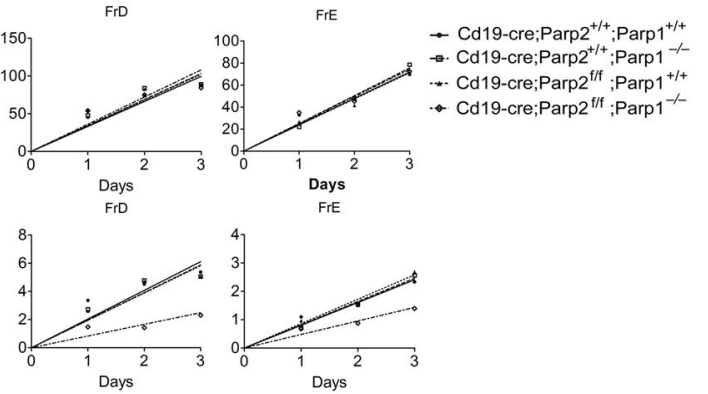

$\mathrm{F}$

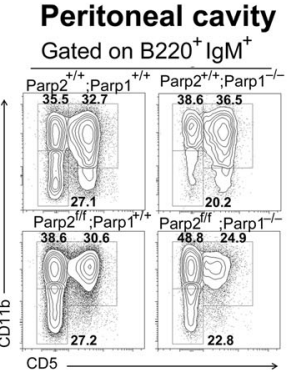

G

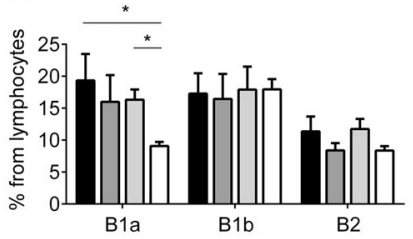

$\mathrm{BrdU}^{+}$-cells of each population by the total number of cells in that population. Each point represents an individual mouse. Lines are those determined by linear regression. d Representative dot-plots showing splenocytes stained for expression of the indicated markers. Percentage of cells in the individual subpopulations with regard to each gate is indicated in each quadrant. Values represent the mean of at least 8 mice of each genotype. e Graph showing total number of spleen cells, and the absolute number of $\mathrm{B} 220^{+}$, transitional B-cells $\left(\mathrm{B} 220^{+} \mathrm{CD} 93^{+}\right.$ gated lymphocytes. $\mathrm{T} 1$ : $\mathrm{IgM}^{\text {high }} \mathrm{CD} 23^{\text {low }}$; $\mathrm{T} 2$ : $\mathrm{IgM}^{\text {high }} \mathrm{CD} 23^{\text {high }}$; $\mathrm{T}$ : $\left.\mathrm{IgM}^{\text {low }} \mathrm{CD} 23^{\text {high }}\right)$, Marginal Zone (MZ) B-cells $\left(\mathrm{CD} 21^{\text {high }} \mathrm{CD} 23^{\text {low }}\right)$, and Follicular (FO) B-cells (CD21 $\left.{ }^{\text {low }} \mathrm{CD} 23^{\text {high }}\right)$. The number of cells in each population was calculated by multiplying the percentage of each population by the total number of splenocytes. Values represent the mean \pm SEM of at least 8 mice of each genotype. f Representative dotplots showing peritoneal cavity cells stained for expression of the indicated markers. Percentage of cells in the individual subpopulations with regard to each gate is indicated in each quadrant. $\mathrm{g}$ Graph showing the percentage of $\mathrm{B} 1 \mathrm{a}\left(\mathrm{B} 220^{+} \mathrm{IgM}^{+} \mathrm{CD}^{+} \mathrm{CD} 11 \mathrm{~b}^{+}\right)$, B1b $\left(\mathrm{B}^{2} 20^{+} \mathrm{IgM}^{+} \mathrm{CD}^{-} \mathrm{CD} 11 \mathrm{~b}^{+}\right)$and $\mathrm{B} 2\left(\mathrm{~B}^{-} 20^{+} \mathrm{IgM}^{+} \mathrm{CD}^{-} \mathrm{CD} 11 \mathrm{~b}^{-}\right)$cells among peritoneal lymphocytes. Values represent the mean \pm SEM of 5 mice of each genotype. $* P<0.05 ; * * P<0.01$

\section{PARP-1 and PARP-2 are dispensable for Ig V(D)J gene recombination}

Given that PARP-1 and PARP-2 are involved in DDR, we hypothesized that impaired B-lymphoid development 
stemmed from defective Ig V(D)J recombination in dual PARP-1 and PARP-2-deficient mice. Accordingly, we generated $v$ - $a b l$ transformed pro-B-cell lines from wild type (WT), Parp1 ${ }^{-/-}$, Parp2 $2^{f f f}$, and Parpl $^{-/}$Parp2 $^{\text {fff }}$ mice (Table S2). Of note, treatment of $v$-abl pro-B-cells with the $v$-abl kinase inhibitor STI571 (ABLki) leads to G1 cellcycle arrest, rapid induction of RAG1 and RAG2 gene expression and rearrangement of the $I g k$ locus or any recombination substrate, thereby providing a pseudophysiological model to study Ig V(D)J recombination [24-26].

To delete Parp2 in Parp $2^{f f f}$ pro-B-cell lines, we infected Parp2 $^{\text {fff }}$ and Parp1 ${ }^{-1-}$ Parp2 $^{\text {fff }}$ pro-B-cells with an MSCVCreE-IRES-Thy1.1 retroviral vector [27], which allows simultaneous expression of the Cre-recombinase and surface Thy1.1 expression. To ascertain the induction of complete Parp2 deletion, we PCR amplified Parp2 floxed alleles in single FACSorted Thy $1.1^{+}$-pro-B-cells (Fig. 3a and Fig. S3). As expected, loss of Parp2 floxed alleles was observed in a majority of Thy $1.1^{+}-$Parp $^{f / f}$ pro-B-cell clones (11 out of 13 clones; $84.6 \%$ ). In sharp contrast, 42 of 90 Thy $1.1^{+}-$Parp $^{-/}{ }^{-}$Parp $2^{\text {fff }}$ pro-B-cell clones analyzed (46.7\%) were Parp2 $2^{\text {fff }}$, whereas 44 (48.9\%) had lost one Parp2 floxed allele, and only 4 (4.4\%) had lost both Parp2 floxed alleles (Fig. 3a). These clones died during the course of the analysis (data not shown). Thus, loss of both PARP-1 and PARP-2 appears to be synthetically lethal in $v-a b l$ proB-cells.

To determine whether removal of the pro-apoptotic $p 53$ gene enables survival of dually PARP-1 and PARP-2deficient $v$-abl pro-B-cell clones, we generated $v$ - $a b l$ pro-Bcell lines from $\operatorname{Parp}^{-1-} \mathrm{Parp}^{\mathrm{fff}} \mathrm{p} 53^{-/-}$mice and infected these cells with MSCV-CRE-IRES-Thy1.1. Unlike p53sufficient Thy $1.1^{+}-$Parp $^{-/-}{ }^{-}$arp $2^{\text {fff }}$ pro-B-cell clones, p53deficient Thy $1.1^{+}-$Parp $^{-/-}$Parp $^{\text {fff }} p 53^{-/-}$pro-B-cell clones showed homozygous deletion of Parp2 floxed alleles (70 out of 81 clones; 86.4\%) (Fig. 3a and Fig. S3). Thus, loss of p53 rescues viability in $v$-abl-transformed proB-cells lacking both PARP-1 and PARP-2.

To measure Ig V(D)J recombination defects, we transduced pro-B-cell lines from each genotype with the pMXRSS-GFP/IRES-hCD4 retroviral recombination substrate (pMX-INV), which allows GFP expression upon RAGmediated recombination [24-26] (Fig. 3b). Flow cytometry showed robust pMX-INV rearrangement in ABLki-treated WT and Parp $2^{\text {fff }}$ pro-B-cells (Fig. 3c). In agreement with in vivo data, PARP-1 deficiency did not significantly alter Ig V(D)J recombination in Parp $^{-/-}$or Parp $1^{-/-}$Parp2 $^{\text {fff }}$ proB-cells as compared to WT cells (Fig. 3c). Similarly, pMXINV rearrangement was not markedly affected in Parp $2^{-1-}$ pro-B-cells, although it was significantly diminished as compared to WT or Parp $2^{f / f}$ controls (Fig. 3c).
We also detected robust pMX-INV rearrangement in Parp $^{-/-}{ }^{-}$arp $2^{f /-}$ pro-B-cells (Fig. 3c), which indicates that Parp2 is haplosufficient in the context of PARP-1 deficiency with respect to Ig V(D)J recombination (Fig. 3c). Remarkably, flow cytometry also revealed robust inversional rearrangement in both ABLki-treated Parpl $^{-/-}$ Parp $2^{f f f} p 53^{-/-}$and Parp $^{-/-}$Parp $^{-/}{ }^{-1} 53^{-/-}$pro-B-cells (Fig. 3d), which indicates that PARP-1 and PARP-2 are dispensable for RAG-mediated Ig V(D)J rearrangement in pro-B-cells. Consistent with this, analysis of endogenous $I g k$ recombination products revealed robust RAG-induced recombination at these loci in the absence of PARP-1 and PARP-2 (Fig. S4).

We next quantified the presence of DNA damageassociated 53BP1 foci in G1-arrested pro-B-cells [28, 29] (Fig. S5). Pro-B-cells lacking double-strand break (DSB) repair capacity harbor 53BP1 foci in the vast majority of ABLki-treated pro-B-cells due to accumulation of unrepaired RAG-induced DSBs [28, 29]. As shown previously in DNA repair proficient pro-B cells [28], we found that only $15.9 \%$ of $p 53^{-/-}$pro-B-cells showed intense 53BP1 foci, the majority of which contained a single distinct spot, although cells were occasionally found to contain two foci (Fig. S5 and Table S3). Similarly, we found that an average of $17.1 \%$ Parp $^{-/-}$Parp $^{f f f} \mathrm{p} 3^{-/-}$and $25.1 \%$ of Parpl $^{-/}$ Parp $2^{-/-} p 53^{-/-}$ABLki-treated pro-B-cells harbored 53BP1 foci, the majority consisted of a single focus (Fig. S5 and Table S3), which indicates that RAG-induced DSB response and repair is not severely impaired in the absence of both PARP-1 and PARP-2.

Although Ig V(D)J recombination and RAG-induced DDR seemed relatively normal in dual PARP-1 and PARP2-deficient pro-B-cells, we tested whether low levels of unrepaired RAG-induced DNA breaks persisted in these cells. Such breaks would lead to chromosomal instability upon re-entry into the cell cycle, as previously reported in the context of end-joining deficiency [28]. To address this possibility, we performed DNA-FISH analysis on chromosome spreads prepared from untreated cycling cells and G1arrested cells that were released back into cell-cycle upon removal of ABLki (Fig. 3e, f and Table S4). Using probes centromeric $(\operatorname{Ig} k V)$ and telomeric $(\operatorname{Ig} k C)$ to the $I g k$ locus together with paint specific for chromosome 6 (Fig. 3e), we quantified the frequency of $I g k$ chromosome breaks and translocations (Fig. 3f and Table S4). Since DNA breaks induce strong p53-dependent G1/S checkpoint in these cells [28], we used Parpl $^{-/}{ }^{-}$arp $2^{\text {fff }} p 53^{-/-}$and Parp1 ${ }^{-/-}$ Parp $2^{-1} p 53^{-/-}$pro-B-cells to perform these experiments (Fig. 3f and Table S4). As a control, we used a previously published p53-deficient pro-B-cell line that harbors low levels of $I g k$-associated chromosomal instability upon RAG-mediated VJ gene recombination [28]. 
A

\begin{tabular}{rccc}
\hline Cell line & Parp2 $^{\mathrm{f} / \mathrm{f}}$ & Parp1 $^{-/-}$Parp2 $^{\mathrm{f} / \mathrm{f}}$ & Parp1 $^{-l-}$ Parp2 $^{\mathrm{f} / \mathrm{f}} \mathrm{p53}^{-l}-$ \\
\hline Total Thy1.1+ cell clones & 13 & 90 & 81 \\
Parp2 f/f clones & 1 & 42 & 3 \\
Parp2 $^{\mathrm{f} /-}$ clones & 1 & 44 & 8 \\
Parp2 $^{--}$clones & 11 & $4(\dagger)$ & 70 \\
\hline
\end{tabular}

B

Chromosomal recombination reporter

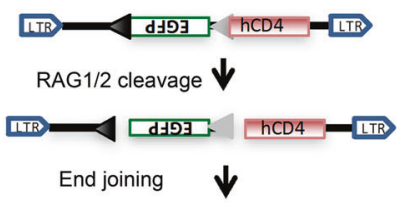

IIR $\longrightarrow$ EGFP $h$ CD4 - LTR

C

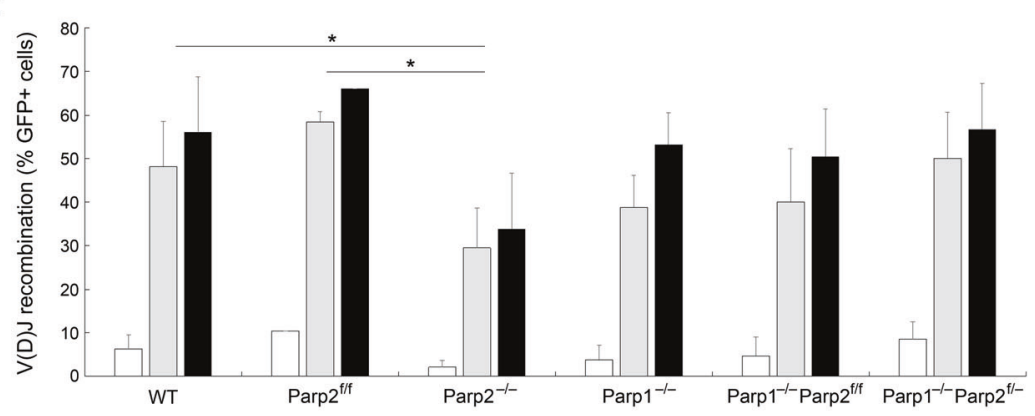

D
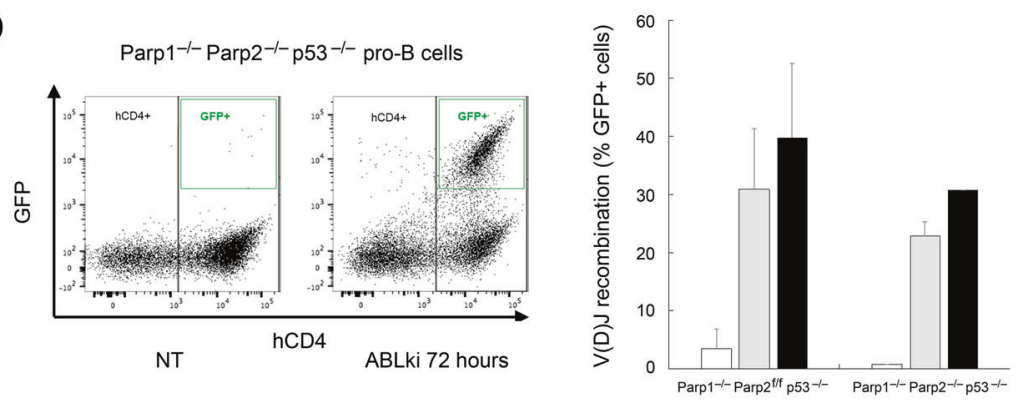

$\mathrm{E}$
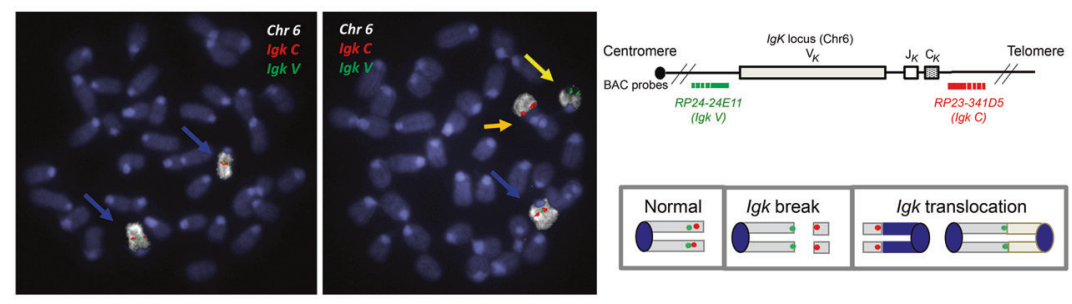

$\mathrm{F}$

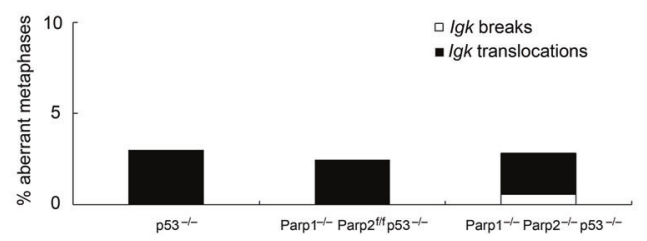

In agreement with results from experiments measuring pMX-INV rearrangement, Ig $k$ rearrangement and 53BP1 foci formation, metaphases prepared from ABLki-released
Parp $^{-/-}$Parp $^{\mathrm{fff}} p 53^{-/-}$and Parp $1^{-/-}$Parp $^{-/-} p 53^{-/-}$proB-cells showed low levels of genomic instability, most notably translocations ( $2.4 \%$ and $3 \%$, respectively; $n=205$ 
Fig. 3 PARP1 and PARP2 are dispensable for V(D)J recombination. a Parp2 genotyping of $v$-abl pro-B-cell clones after pMSCV-CREIRES-Thy1.1 infection and single cell sorting. Number of cell clones genotyped is indicated. See also Fig. S3. ${ }^{\dagger}$ indicates that the clone died during cell expansion. b Schematic of pMX-INV recombination substrate. The 12-recombination signal sequence (RSS-12; black triangle), GFP cDNA, 23-recombination signal sequence (RSS-23; gray triangle), IRES - human CD4 cDNA (hCD4) and LTRs are indicated. c, d pMX-INV $v$-abl pro-B-cell lines untreated (white bars) or treated for $72 \mathrm{~h}$ (gray bars) and $96 \mathrm{~h}$ (black bars) with ABLki were assayed for pMX-INV rearrangement by flow cytometry, with the percentage of GFP expressing cells among total hCD4 positive cells indicated. Data represent the means \pm SEMs of at least two independent experiments using wild type (WT), Parp2 $2^{\text {fff }}$, Parp2 $2^{-/-}$, Parp1 $^{-/-}$, Parp1 $^{-/-}$ Parp2 $^{f / f}$, Parp1 $1^{-/-}$Parp2 $^{f /-}$, Parp1 $1^{-/-}$Parp $^{f / f} p 53^{-/-}$and Parp1 $1^{-/-}$ Parp $^{-/-} p 53^{-1-}$ cell lines described in Table S2. $* P<0.05$. d, left panel Representative FACS plots of pMX-INV rearrangement before treatment (not treated, NT) and after $72 \mathrm{~h}$ of ABLki treatment (ABLki). e, f Genomic instability at the $I g k$ locus in $v$-abl pro-B-cell lines. e Schematics of the Igk locus and chromosome 6, with positions of the BACs used for generation of DNA-FISH probes indicated. Representative metaphases from Parpl $^{-/-}$Parp2 $^{-/} p 53^{-/-} v$-abl pro-Bcells using the $\operatorname{Igk} C$ BAC probe (red) combined with $I g k V$ BAC probe (green) and chromosome 6 paint (white). Blue arrowheads point to normal chromosome 6 , yellow arrowhead point to broken and orange arrowhead to translocated chromosome 6. f Percentage of aberrant metaphases from $v$-abl pro-B-cell lines of the indicated genotype harboring chromosomes breaks (white) or translocations (black) involving the Igk locus. (See also Table S4)

or 499) similar to $p 53^{-/-}$pro-B-cells $(3 \% ; n=101)$ (Fig. $3 \mathrm{f}$ and Table S4). Altogether, these results indicate that PARP1 and PARP-2 are dispensable for RAG-induced Ig V(D)J recombination in G1-arrested pro-B-cells.

\section{PARP-1 and PARP-2 attenuate B-cell death}

B-cell depletion in dually PARP-1 and PARP-2-deficient mice could stem from an impairment of B-cell proliferation, B-cell survival or both. Proliferating $\mathrm{BrdU}^{+} \mathrm{B}$-cells from the bone-marrow of dually PARP-1 and PARP-2-deficient mice were comparable to the other three genotypes (Figs. 2c and 4a). These data indicate that bone-marrow B-cells with dual PARP-1 and PARP-2 insufficiency can normally initiate DNA synthesis. Accordingly, splenic B-cells from dually PARP-1 and PARP-2-deficient mice showed no alteration of the cell-cycle profiles upon exposure to LPS compared to control as well as single PARP-1 or PARP-2deficient B-cells (Fig. 4b, c).

LPS-activated splenic B-cells from dually PARP-1 and PARP-2-deficient mice exhibited increased phosphorylation of histone H2AX (Fig. 4d-f), a hallmark of DNA damage. This increase on $\gamma \mathrm{H} 2 \mathrm{AX}$ was limited to $\mathrm{S} / \mathrm{G} 2$ cells (Fig. 4g), which indicates replicative-stress [30, 31]. We next subjected LPS-activated B-cells to an alkaline-comet assay. We observed a significant increase of dual PARP-1 and PARP-2-deficient B-cells exhibiting comet shape compared to control and single PARP-1 or PARP-2deficient B-cells (Fig. 4h, i). In agreement with these results, a significant increase in apoptotic cells was observed in dually PARP-1 and PARP-2-deficient B-cells compared to control and single PARP-1 or PARP-2deficient B-cells (Fig. 4j). Thus, B-cells with combined PARP-1 and PARP-2-deficiency proliferated in response to the lymphopenic environment, but accumulated DNA damage that caused cell death at a faster rate.

\section{PARP-1 and PARP-2 are required for antibody responses to $\mathrm{TI}$ but not TD antigens}

To determine the role of PARP-1 and PARP-2 in B-cell antibody production under steady-state conditions, we measured the serum concentration of immunoglobulins in non-immunized control, single PARP-1-deficient, single PARP-2-deficient and dual PARP-1 and PARP-2-deficient mice. We found that serum IgM, IgG1, IgG2a, IgG2b, and IgG3 were comparable in mice from the four groups (Fig. S6). Next, we determined whether B-cell-specific deletion of PARP-2 in PARP-1-sufficient or PARP-1deficient mice altered antibody responses to TI or TD antigens. Compared to single PARP-1-deficient or single PARP-2-deficient mice and control mice, dually PARP-1 and PARP-2-deficient mice showed decreased TNP-specific IgG1, IgG2a, IgG2b, and IgG3 responses upon immunization with TNP-LPS (Fig. 5a), which is a type-I TI antigen. Similarly, dually PARP-1 and PARP-2-deficient mice showed reduced TNP-specific responses upon immunization with TNP-Ficoll (Fig. 5b), which is a type-II TI antigen. Conversely, single PARP-1-deficient mice showed increased TNP-specific IgG1, and $\operatorname{IgG} 2 \mathrm{~b}$ responses to TNPFicoll (Fig. 5b). Unlike TI antigens, the TD-antigen TNPKLH elicited comparable TNP-specific antibody responses and similar percentage of germinal centers B-cells in dual or single PARP-1 and PARP-2-deficient mice or controls (Fig. 5c, d). Of note, similar percentage of germinal centers B-cells was also observed in Peyer's patches from all genotypes (Fig. S7).

To assess the role of PARP-1 and PARP-2 in B-cell class switching, we stimulated purified splenic resting B-cells with LPS with or without IL-4 or INF- $\gamma$ during 3 days. We found that B-cells with dual PARP-1 and PARP-2deficiency underwent class switching at a frequency comparable to that of B-cells with single PARP-1 or PARP-2 deficiency (Fig. 5e, f). Thus, PARP-1 and PARP-2 are required for class-switched $\mathrm{IgG}$ responses to some but not all antigens as a result of their essential role in B-cell development and homeostasis but not as a result of their Bcell-intrinsic CSR-inducing activity. 
A

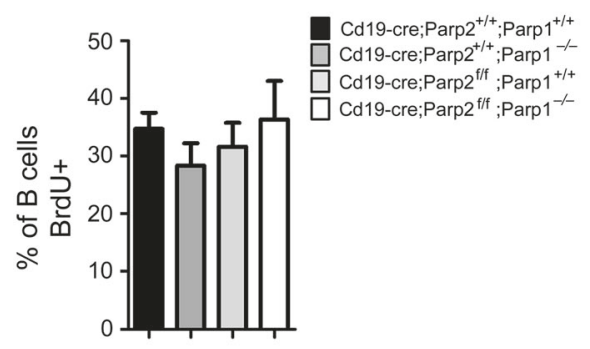

D

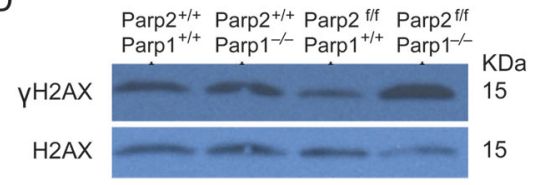

$\mathrm{E}$

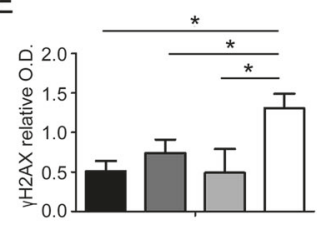

$\mathrm{H}$

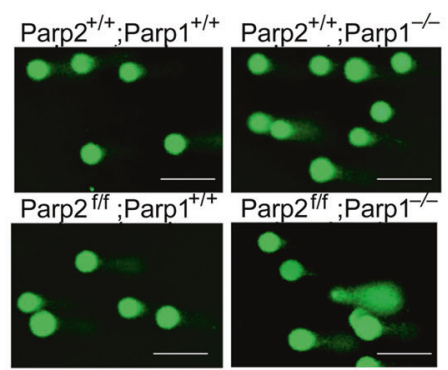

Fig. 4 Cell-cycle profiles, DNA damage and apoptosis in PARP-1/ PARP-2-doubly deficient splenic B-cells. a In vivo proliferation of bone-marrow B-cells was determined by intraperitoneal injection of 68 -weeks-old mice of the indicated genotypes with $\operatorname{BrdU}(1 \mathrm{mg})$ at $12 \mathrm{~h}$ intervals. Bone-marrow was harvested at $24 \mathrm{~h}$ after the onset of injection and BrdU incorporation on B cells was analyzed by flow cytometry. Bars represent the mean \pm SEM values of the percentage of $\mathrm{BrdU}^{+} \mathrm{B}$-cells obtained from 6 mice per genotype. b, c B-cells from spleen of mice of the indicated genotype were culture in the presence of LPS $(10 \mu \mathrm{g} / \mathrm{ml})$. After $36 \mathrm{~h}$ in cultured, cells were pulsed with EdU for 60 min. Click-iT EdU kit from ThermoFisher was used to detect replicating cells and DAPI was used to determine DNA content. b Representative cell-cycle profiles from three independent experiments. c Percentage of cells that are in G0/G1, S and G2/M phases of cellcycle. Bars represent the mean \pm SEM obtained from 6 mice per genotype. d B-cells from spleen of mice of the indicated genotype were culture in the presence of LPS $(10 \mu \mathrm{g} / \mathrm{ml})$. After $36 \mathrm{~h}$ in cultured,

\section{Discussion}

Here, we have found that combined expression of the DNA repair enzymes PARP-1 and PARP-2 promotes central Bcell development and sustains peripheral B-cell homeostasis, including antibody responses to TI antigens but not
C

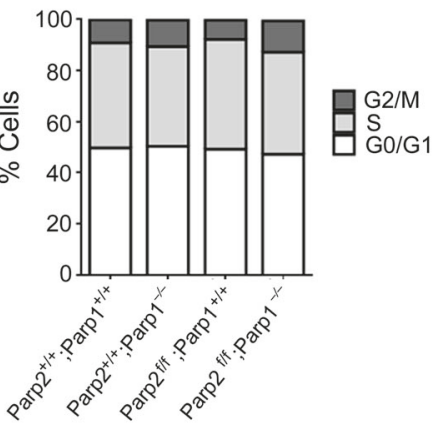

G

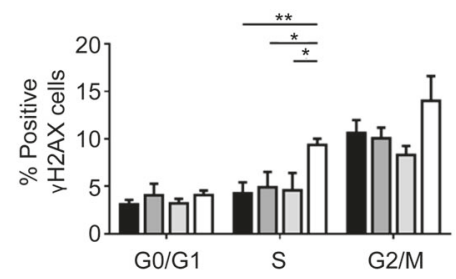

cells were collected and protein extracts were prepared. A representative western-blot of $\gamma-\mathrm{H} 2 \mathrm{AX}$ and $\mathrm{H} 2 \mathrm{AX}$ protein expression. e Densitometry analysis (optical density) of $\gamma$-H2AX bands from western blotting. f Representative flow cytometry histograms showing $\gamma$ $\mathrm{H} 2 \mathrm{AX}$ protein levels (on the basis of mean fluorescence intensity) in $\mathrm{B}$-cells from spleen of mice of the indicated genotype after culture for $36 \mathrm{~h}$ in the presence of LPS $(10 \mu \mathrm{g} / \mathrm{ml})$. $\mathrm{g}$ Graph showing the percentage of $\gamma$-H2AX-positive cells in G0/G1, S and G2/M phases of cell-cycle in B-cells from spleen of mice of the indicated genotype after culture for $36 \mathrm{~h}$ in the presence of LPS $(10 \mu \mathrm{g} / \mathrm{ml})$. h Representative images showing DNA damage in B-cells after stimulation for $36 \mathrm{~h}$ with LPS, visualized by alkaline-comet assay. i Graph showing the percentage of cells with comet. An average of 100 cells was scored from each mouse. $\mathbf{j}$ Bars represent the percentage of B-cells positive for active caspase- 3 after $36 \mathrm{~h}$ of culture in the presence of LPS. The results are expressed as mean \pm SEM. $* P<0.05$; $* * P<0.01$; *** $P<$ 0.001

TD antigens. Despite the crucial role of PARP-1 and PARP2 in DDR, these enzymes were dispensable for both Ig V(D) $\mathrm{J}$ gene recombination and CSR. Indeed, PARP inhibitors are a rapidly evolving class of drugs that prevent cancer cells from repairing damaged DNA thereby causing them to die [32]. Hence, a better understanding of the function of 
A

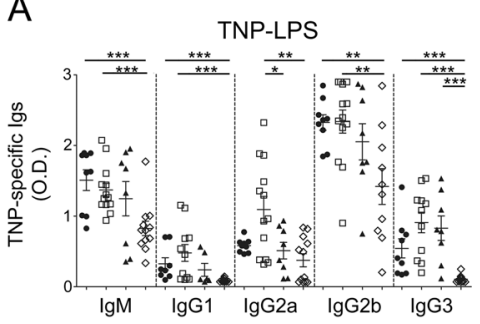

B

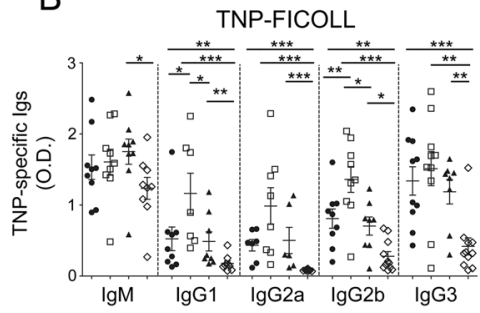

C

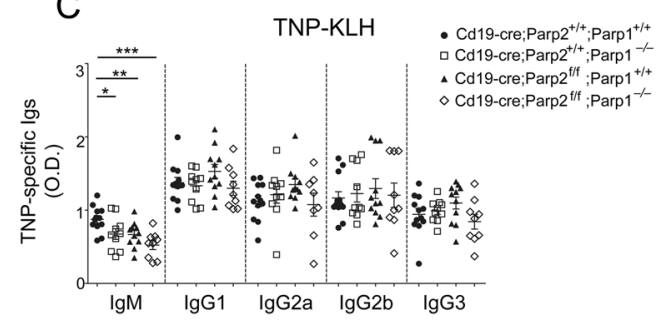

D

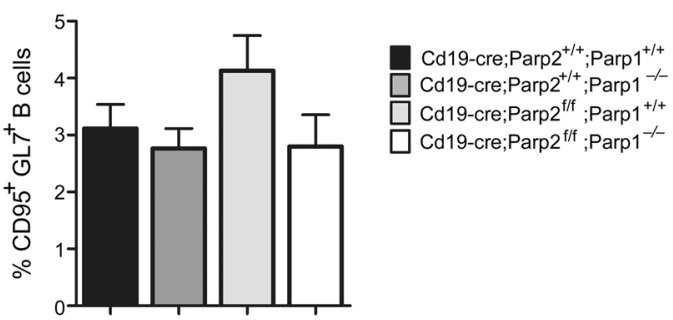

$\mathrm{F}$

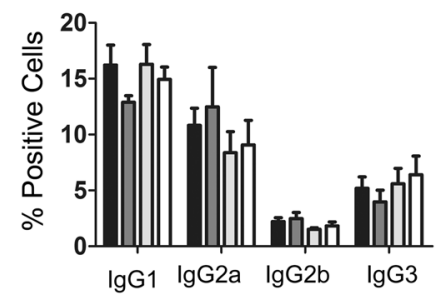

Fig. 5 PARP-1/PARP-2 doubly deficiency in B-cells causes faulty Tindependent but not T-dependent immune responses. 8-10-weeks-old mice of the indicated genotypes were immunized i.p. with a type-I T cell-independent (TNP-LPS), b type-II T cell independent (TNPFicoll), or c T cell-dependent (TNP-KLH) antigens. Fourteen days after immunization, TNP-specific IgM, IgG1, IgG2a, IgG2b, and IgG3 were evaluated in the sera by ELISA. Dots represent individual mice from two independent immunization experiments and horizontal lines represent median values. $* P<0.05 ; * * P<0.01 ; * * * P<0.001$. d Fourteen days after TNP-KLH immunization, spleen was analyzed for the presence of germinal center $\left(\mathrm{CD} 95^{+} \mathrm{GL} 7^{+}\right)$B cells. Bars represent

PARP1 and PARP2 in proliferating immune cells such as B-lymphocytes is becoming a pressing need to design better PARP-targeting agents devoid of harmful off-target effects on the humoral arm of the immune system.

A key finding of our study is that mice with dual but not individual PARP-1 and PARP-2 deficiency showed loss of B-cells in the bone-marrow, which started at pre-B cell stage. Considering that PARP deficiency could cause central B-cell death by preventing the repair of double-strand DNA lesions brought about by RAG-mediated Ig gene $\mathrm{V}$ (D)J recombination, one possible explanation of our finding is that PARP-1 and PARP-2 can compensate for the lack of one or the other during Ig V(D)J recombination. Our data rule out any major role of either PARP-1 or PARP-2 in Ig V (D)J recombination. Moreover, our findings show that Bcells with combined PARP-1 and PARP-2 deficiency remain proficient in the execution of $\operatorname{Ig} \quad \mathrm{V}(\mathrm{D}) \mathrm{J}$
E

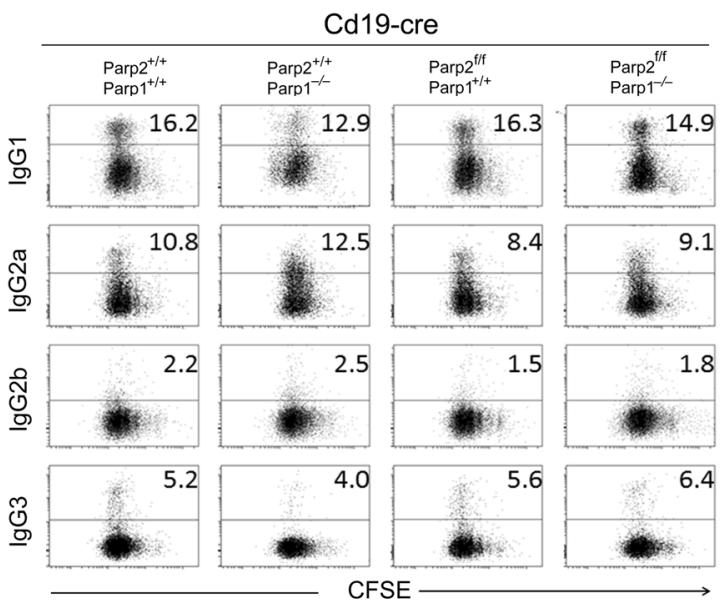

the percentage of germinal center B lymphocytes for the indicated genotype. Values represent the mean \pm SEM of at least 4 mice of each genotype. e Representative dot-blot showing the surface expression of IgG1, IgG2a, IgG2b, IgG3, and CFSE dilution analyzed by flow cytometry in B-cells from the indicated genotypes, stimulated for $72 \mathrm{~h}$ with either LPS + IL-4 (CSR to IgG1) or LPS (CSR to IgG2b and IgG3) or LPS + IFN- $\gamma$ (CSR to IgG2a). The percentage of switched cells is indicated. f Bars represent the percentage of B lymphocytes positive for the indicated Ig isotype. Data are representative of four independent experiments

recombination. Considering that RAG-mediated repair of DSBs is restricted to the G1 phase of the cell-cycle, we propose that the DNA repair activity of PARP-1 and PARP2 is very limited in non-cycling B-cells.

An alternative explanation for the B-cell lymphopenia in dually PARP-1 and PARP-2-deficient mice could relate to a shift in the balance between proliferation and survival during B-cell development, with homeostatic expansion aimed at replenishing the B-cell niche [33, 34]. Indeed, our data show that peripheral B-cells from mice with dual PARP-1 and PARP-2 deficiency normally enter the S phase of the cell-cycle upon receiving a polyclonal proliferationinducing stimulus. However, these activated B-cells show increased death.

Consistent with the important role of PARP-1 and PARP-2 in maintaining genomic stability [7], we found that these DNA repair enzymes function in a redundant manner 
in actively proliferating B-cells and may do so to prevent the accumulation of toxic levels of unrepaired DNA damage. Indeed, this damage could cause death during homeostatic or antigen-induced B-cell proliferation. This interpretation is consistent with recent results showing that dual PARP-1 and PARP-2 deficiency causes accumulation of replication-derived DNA damage owing to the cell's inability to stabilize Rad51 at damaged DNAreplication forks and thereafter prevent uncontrolled DNA resection [35].

According to the principle of synthetic lethality, which posits that combined but not isolated lesions of two distinct genes result in cell death [36], PARP-1 and PARP-2 may regulate two independent but functionally linked processes. In particular, they may promote base excision repair directly while stabilizing replication forks that encounter base excision repair intermediates [35]. Such mechanism could explain the PARP-1 and PARP-2 synthetic lethality that we observed in the context of $v-a b l$ transformed pro-B-cells. As previously demonstrated by our group [18], PARP-1 and PARP-2 would exerts a similar function in T cells, raising the possibility that there is a master mechanism that allows the PARP system to maintain genomic stability during the proliferation of the lymphoid compartment.

Remarkably, the impaired central B-cell development detected in dually PARP-1 and PARP-2-deficient mice did not yield comparable consequences in FO and MZ B-cells, as combined PARP-1 and PARP-2 deficiency dampened the size of FO but not MZ B-cell pools. This finding raises the possibility that PARP-1 and PARP-2 deploy important but somewhat redundant functions in the development and/or homeostatic maintenance of the FO but not MZ B-cell compartments. Accordingly, several genes are essential for maintaining FO but not MZ B-cells, including c-myb [37], Akirin2 [38], Flt3-ligand [39], and DKK3 [40]. An explanation for the observed dichotomy of FO and MZ B-cell fate in dually PARP-1 and PARP-2-deficient could relate to the longer lifespan and self-renewal capability of $\mathrm{MZ}$ compared to FO B-cells [2].

The peripheral B-cell lymphopenia detected in dually PARP-1 and PARP-2-deficient mice was associated with an impairment of antibody responses to TI but not TD antigens. This finding was somewhat unexpected, as TI and TD antigens mainly induce antibody production by stimulating MZ and FO B-cells [3], which are conserved and depleted in dually PARP-deficient mice, respectively. However, a normal MZ B-cell number does not necessarily correlate with a conserved functionality. For instance, $S h 3 b p 2^{-1-}$ and Hipk1 $^{-1-}[41,42]$ mice show an increased MZ B-cell compartment but poor antibody responses to TI antigens. Conversely, these responses can be normal in mice with a depleted MZ B-cell compartment [43].
Clearly, further studies are needed to determine how PARP-1 and PARP-2 preserve the functionality of MZ Bcells as they respond to a TI antigen. This response has innate-like properties that ultimately lead to an explosive extrafollicular differentiation and expansion of antibodysecreting plasmablasts [3]. One possibility is that PARP-1 and PARP-2 deploy coordinated signals to specifically control the proliferation of these plasmablasts instead of their MZ B-cell precursors. Remarkably, MZ B-cells can be also recruited into antibody responses to TD antigens [3], which could explain why these responses were normal in dually PARP-1 and PARP-2-deficient mice, despite their overt depletion of FO B-cells. Alternatively, the surviving FO B-cells from these mice may have a compensatory increase of their proliferation, survival, and/or differentiation properties, including plasmablastassociated antibody secretion, which could make up for their depletion.

In summary, we found that central B-cell development and peripheral B-cell homeostasis are impaired in mice with combined but not individual PARP-1 and PARP-2 deficiency. In the periphery, this impairment mainly features depletion of FO but not MZ B-cells as well as impaired antibody responses to TI but not to TD antigens. Notwithstanding the pivotal role of PARP-1 and PARP-2 in DNA repair, combined PARP-1 and PARP-2 deficiency did not perturb Ig V(D)J recombination and IgM-to-IgG CSR. These findings may facilitate the development of safer PARP-targeting regimens against cancer with reduced offtarget effects on the immune system.

\section{Materials and methods}

\section{Mice}

Parp-2 $2^{f l o x f l o x}\left(\right.$ Parp-2 $\left.2^{\text {fff }}\right)$, Parp- $-^{-/-}$and transgenic mice for Cre-recombinase driven by the $C d 19$ promoter (Cd19-cre) have been described $[18,23,44] . \mathrm{p}^{-1-}$ mice were from Jackson Laboratory (Bar Harbor, ME). Genotyping was performed by PCR analysis using tail DNA. Parp-2 $2^{\text {flox }}$, Parp-1, and p53 genotyping has been described [16, 18, 45]. Cd19cre was genotyped using the following primers: CD19f_22B5 AGGGAGGCAATGTTGTGCT; CD19r_22B6 TGCCAG ACCAAAGAACTTCCTC; CreR_6B3 GTTCGAACGCT AGAGCCTGTTT. All mice had C57BL/6J background and were reared under pathogen-free conditions. The PRBB Institutional Animal Care and Use Committee approved the studies and all experiments were performed in accordance with relevant guidelines and regulations. Parp-2 deletion on genomic DNA was confirmed by PCR analysis on FACSorted bone-marrow and spleen populations. 


\section{PARP activity}

Protein extracts were prepared from purified B-cells upon LPS stimulation $(10 \mu \mathrm{g} / \mathrm{ml}$; Sigma-Aldrich) for 2.5 days as previously described [46]. PARP activity was determined by using $10 \mu \mathrm{g}$ of total protein and the HT Universal Colorimetric PARP Assay Kit with Histone-Coated Strip Wells (Trevigen) following manufacturer's instructions.

\section{Western-blot}

Cell lysates were prepared homogenizing PBS-washed cells in SDS-sample buffer (67 mM Tris-HCl (pH 6.8), 5\% (v/v) $\beta$-mercaptoethanol, 2\% (w/v) SDS, 0.01\% (w/v) Bromophenol blue, $10 \%$ (v/v) glycerol). Proteins were resolved by SDS-PAGE, and analyzed by standard western blotting techniques, using the following antibodies: PARP-1 (clone A6.4.12), in-house generated affinity purified rabbit polyclonal antibody raised against PARP-2 residues 1-69 fused to GST, and $\beta$-Actin (Sigma-Aldrich, clone AC-15). Primary antibody binding was detected using peroxidasecoupled rabbit anti-mouse (GE Healthcare) or goat-antirabbit Ig antibodies (Dako) according to the manufacturer's protocol.

\section{Flow cytometry and cell sorting}

Cell suspensions were recovered from bone-marrow, spleen, lymph nodes, Peyer's patches and peritoneal cavity of mice, washed in PBS, resuspended in PBS containing $0.5 \% \mathrm{BSA}$ and incubated with antibodies on ice for $30 \mathrm{~min}$. Incubation with biotin-labeled antibodies was followed by incubation with streptavidin conjugates. For intracellular staining, cells were stained for cell-surface markers, fixed and made permeable by using an intracellular staining buffer set (BD Biosciences), and then stained with specific antibody or isotype control. Red Blood Cells (RBC) were lysed using ACK lysis buffer (BioWhitaker). The following antibodies were used: APC-Cy7-conjugated CD3 (17A2; BD Biosciences), PerCP- and APC-conjugated CD45R (B220) (RA3-6B2; BD Biosciences), PE-, FITC, and APCCy7-conjugated IgM (R6-60.2; BD Biosciences), APCCy7-conjugated CD43 (S7; BD Biosciences), APC and FITC-conjugated CD21 (7G6; BD Biosciences), FITC and PE-conjugated CD23 (B3B4; BD Biosciences), PerCP/ Cy5.5-conjugated CD93 (AA4.1; BioLegend), PEconjugated CD25 (3C7; BioLegend), APC-Cy7conjugated CD117 (2B8; BioLegend), PE-Cy5-conjugated CD5 (53-7.3; BioLegend), FITC-conjugated GL-7 (GL7; BioLegend), PE-conjugated CD95 (Jo2; BD Biosciences), FITC-conjugated CD11b (M1/70; BioLegend), Alexa Fluor-555-conjugated phospho-H2AX (S139) (JPW301; Millipore), FITC-conjugated active caspase-3 (rabbit polyclonal antibody; BD Biosciences), biotin-conjugated IgM (R60.2; BD Biosciences), biotin-conjugated IgG1 (A85-1; BD Biosciences), biotin-conjugated IgG2a (R1915; BD Biosciences), biotin-conjugated IgG2b (R12-3; BD Biosciences), biotin-conjugated IgG3 (R40-82; BD Biosciences), APC-conjugated streptavidin (BD Biosciences). Cell doublets were excluded from all analyses and dead cells were excluded by the use of DAPI. Samples were acquired with a Fortessa cytometer (BD Biosciences) and the data analyzed with the DIVA (BD Biosciences) and FlowJo (TreeStar) softwares. Cell sorting was performed in a FACS AriaIISORP (BD Biosciences).

\section{BrdU incorporation}

Mice received intraperitoneal injections of BrdU (BD Biosciences; $1 \mathrm{mg}$ per mouse) every $12 \mathrm{~h}$ and were sacrificed at 24, 48, and $72 \mathrm{~h}$. Bone-marrow cells were surfacestained, fixed, permeabilized, and intracellularly stained using a BrdU Flow kit (BD Biosciences).

\section{Cell-cycle, DNA damage, and apoptosis}

Untouched purified B-cells from spleen were cultured for $36 \mathrm{~h}$ in RPMI media supplemented with $10 \%$ FBS in the presence of LPS $(10 \mu \mathrm{g} / \mathrm{ml})$. Cells were then pulsed with $10 \mu \mathrm{M}$ 5-ethynyl-2'-deoxyuridine (EdU) for $60 \mathrm{~min}$ at $37^{\circ} \mathrm{C}$, and then processed with the Click-iT flow cytometry kit (ThermoFisher Scientific) according to the manufacturer's protocol, and analyzed by flow cytometry. For detection of active caspase- 3 and $\gamma$-H2AX, cells were harvested at $36 \mathrm{~h}$ after stimulation with LPS $(10 \mu \mathrm{g} / \mathrm{ml})$, stained for cell-surface markers, fixed, and made permeable by using an intracellular staining buffer set (BD Biosciences), and then stained with specific antibody or isotype control, and analyzed by flow cytometry. Alkaline-comet assay on LPS-activated B-cells was performed with CometAssay kit (Trevigen) following manufacturer's instructions.

\section{Class-switching assays}

Untouched B-cells were isolated from spleens of 8-12weeks-old mice by magnetic depletion of non-B-cells using a MACS Pan-B-cell isolation kit, according to the manufacturer's instructions (Miltenyi Biotec). Purity was assessed by flow cytometry analysis using antibodies against B220 and all preparations were more than $98 \%$ pure B-cells. Cells were resuspended in RPMI media supplemented with $10 \%$ fetal bovine serum (FBS), seeded in 96-well plates $\left(2 \times 10^{5}\right.$ cells per well). For in vitro class-switching analysis, B-cells were harvested at day 3 after stimulation with LPS $(10 \mu \mathrm{g} / \mathrm{ml}), \quad$ LPS + IL-4 $(50 \mathrm{ng} / \mathrm{ml} ;$ Peprotech $)$, or LPS + IFN- $\gamma$ (10 ng/ml; Peprotech), stained for surface 
expression of $\operatorname{IgM}$, IgG1, IgG2a, IgG2b, or $\operatorname{IgG} 3$, and analyzed by flow cytometry.

\section{Immunizations}

To test $\mathrm{T}$ cell-dependent responses, 8-12-weeks-old animals were immunized intraperitoneally with $100 \mu \mathrm{g} /$ mouse of trinitro-phenyl-conjugated keyhole limpet hemocyanin (TNP-KLH) (Biosearch Technologies) in Sigma Adjuvant System (Sigma-Aldrich). For T cell-independent responses, mice were immunized intraperitoneally with either $20 \mu \mathrm{g} /$ mouse of TNP-LPS (Type I; Sigma-Aldrich) or $40 \mu \mathrm{g}$ / mouse of TNP-Ficoll (Type II; Biosearch Technologies). Serum was collected from tail vein before injection and 14 days after immunization.

\section{Enzyme-linked immunosorbent assays (ELISA)}

To determine the concentration of basal serum immunoglobulins, 96-well plates (BD Biosciences) were coated with antibody (IgM (II/41), IgG1 (A85-3), IgG2a (R11-89, IgG2b (R9-91), and IgG3 (R2-38), (all from BD Biosciences) in $\mathrm{PBS} / \mathrm{Tris}-\mathrm{HCl} 0.1 \mathrm{M}$ at $5 \mu \mathrm{g} / \mathrm{ml}$ overnight at $4{ }^{\circ} \mathrm{C}$. Isotype standards Abs were obtained from SigmaAldrich. TNP-BSA (Biosearch Technologies) was used to coat plates for detecting TNP-specific Ig in the sera of immunized mice. After blocking with PBS and 1\% BSA, dilutions of mouse serum were added, and again plates were incubated overnight at $4{ }^{\circ} \mathrm{C}$. The following day, biotinylated anti-mouse IgM (R60.2), IgG1 (A85.1), IgG2a (R19-15), IgG2b (R12-3), and IgG3 (R40-82) secondary antibodies (BD Biosciences) were added and plates were incubated for $1 \mathrm{~h}$ at room temperature. After washing, the plates were incubated with streptavidin-horseradish peroxidase (Dako) for $1 \mathrm{~h}$ at room temperature. Following washing, 3,3',5,5'Tetramethylbenzidine (Sigma-Aldrich) was added and the plates were read at $655 \mathrm{~nm}$.

\section{Generation of v-abl transformed pro-B-cell lines}

Total bone-marrow from 4-8-weeks old mice of each genotype (i.e., wild type; Parp1 $^{-/-} ;$Parp $^{\text {flox/flox }} ;$ Parpl $^{-/-}$ Parp $2^{\text {floxflox }} ;$ Parp $^{-1-}$ Parp $\left.2^{\text {flox/flox }} p 53^{-/-}\right)$were used to generate viral-Abelson kinase $(v-a b l)$ immortalized pro-Bcell lines [24, 47]. $v$ - $a b l$ transformed pro-B-cell lines were transduced with pMSCV-Bcl2-puro retrovirus to protect them from ABL kinase inhibitor-induced cell death [24, 28]. v-abl Parp2 floxed pro-B-cell lines were subsequently transduced with pMSCV-CRE-IRES-Thy1.1 retrovirus [27]. The next day, single cells expressing Thy1.1 were sorted using a BD FACSAria ${ }^{\mathrm{TM}}$ cell sorter into 96well plates and, after $\sim 2$ weeks of culture, cell clones were genotyped using the following primers: Parp2 floxed allele forward: CTCGAGTGTTTCACTGTGAGGGAG; Parp2 floxed allele reverse: CCCCAAACCAGAGTCCCATCC, Parpl wild-type allele: GGCCAGATGCGCCTGTCCAA GAAG, Parp1 wild type and null alleles: CTTGATGG CCGGGAGCTGCTTCTTC, Parp1 null allele: GGCGAG GATCTCGTCGTGACCCATG.

\section{Ig $V(D) J$ gene recombination assay}

The pMX-INV substrate was introduced in pro-B-cell lines or clones through retroviral infection and cells that had integrated the recombination substrate were enriched based on hCD4 expression [24]. For V(D)J recombination assay, $v$-abl transformed pMX-INV infected pro-B-cells $\left(10^{6} / \mathrm{ml}\right)$ were treated with $3 \mu \mathrm{M}$ of the $\mathrm{ABL}$ kinase inhibitor (ABLki) STI571 (Novartis) and assayed for rearrangement by FACS analysis of GFP expression at 0,72 , or $96 \mathrm{~h}$. V(D) $\mathrm{J}$ recombination efficiency was scored as the percentage of GFP positive cells among hCD4 positive cells. For ABLki release experiments (i.e., analysis of RAG-induced genetic instability in pro-B-cells), cells were collected, washed, and cultured without ABLki for 3-4 days before metaphases preparation.

\section{Metaphase preparation}

Metaphases were prepared using standard procedures [24]. Briefly, cells were incubated with colcemid $(0.03 \mu \mathrm{g} / \mathrm{ml}$, Life technologies, KaryoMAX Colcemid Solution) for 3-4 $\mathrm{h}$ at $37^{\circ} \mathrm{C}$. Then, cells were collected and incubated in $0.075 \mathrm{M} \mathrm{KCl}$ for $10 \mathrm{~min}$ at $37^{\circ} \mathrm{C}$, fixed in fixative solution ( $75 \%$ methanol $/ 25 \%$ acetic acid) and washed three times in the fixative. Cell suspension was dropped onto humid slides and air-dried for further analysis.

\section{DNA-FISH probes}

BAC probes RP24-243E11 (5' Igk V) and RP23-341D5 (3' Igk C) were directly labeled by nick translation with ChromaTide Alexa Fluor 488- and 594-5-dUTP (Life technologies), as previously described [48]. Nick translation reaction was optimized to get a DNA smear between $100 \mathrm{bp}$ and $600 \mathrm{bp}$. Labeled BAC probes were purified using Illustra MicroSpin G-50 Columns (GE Healthcare). $600 \mathrm{ng}$ of each locus specific BAC probes were pooled and precipitated with mouse Cot1 DNA and Salmon Sperm DNA (Life Technologies). Probes were then resuspended in hybridization buffer (10\% dextran sulfate, 5X Denharts solution, $50 \%$ formamide), denatured for $5 \mathrm{~min}$ at $95^{\circ} \mathrm{C}$ and pre-annealed for $30-45 \mathrm{~min}$ at $37^{\circ} \mathrm{C}$. XCyting Mouse Chromosome 6 (Orange) paint from MetaSystems were 
denatured for 5 min at $95^{\circ} \mathrm{C}$ and mixed with BAC probes just before hybridization.

\section{DNA-FISH on metaphase spreads}

Slides were treated with RNase A for 40 min, dehydrated in $70 \%, 90$ and $100 \%$ ethanol for $3 \mathrm{~min}$ each, denatured in $70 \%$ formamide $/ 2 \times \mathrm{SSC}$ for $3 \mathrm{~min}$ at $77^{\circ} \mathrm{C}$, dehydrated again in cold ethanol series, and hybridized with probes o/n at $37^{\circ} \mathrm{C}$ in a humid chamber. The next day, slides were washed three times in $50 \%$ formamide $/ 0.5 \times$ SSC for $5 \mathrm{~min}$ each at $37^{\circ} \mathrm{C}$ and twice in $0.5 \times$ SSC for $10 \mathrm{~min}$ each at $37^{\circ} \mathrm{C}$. Finally, slides were mounted in ProLong Gold (Life Technologies) containing 49,6-diamidino-2-phenylindole (DAPI) to counterstain total DNA. Metaphases were imaged using a ZEISS AxioImager.Z2 microscope and the Metafer automated capture system (MetaSystems), and counted manually.

\section{BP1 immunofluorescence on interphase nuclei}

After $65 \mathrm{~h}$ treatment with ABLki, pro-B-cell lines were adhered to poly-L lysine-coated coverslips and stained as previously described $[29,48]$. Cells were fixed with $4 \%$ paraformaldehyde/PBS for $10 \mathrm{~min}$ at room temperature (RT) and permeabilized for $5 \mathrm{~min}$ with $0.4 \%$ Triton/PBS on ice. Immunofluorescence was performed after $30 \mathrm{~min}$ blocking in $2.5 \%$ BSA $/ 10 \%$ Goat Serum/0.1\% Tween-20/PBS, with a primary antibody against 53BP1 (NB100-304SS, 1:1000 dilution, Novus Biologicals) and a secondary goat-anti-rabbit antibody (Alexa Fluor 594, 1:1000 dilution; Life Technologies) in blocking solution, for $1 \mathrm{~h}$ each at RT. Cells were washed three times with $0.5 \%$ BSA/0.1\% Tween-20/PBS after both primary and secondary antibody incubations. Finally, slides were mounted in ProLong Gold (Life Technologies) containing DAPI to counterstain total DNA. Cells were imaged in 3D (9 Z stacks of $0.5 \mu \mathrm{m})$ using a Zeiss Axiolmager Z2 microscope and the Metacyte automated capture system (Metasystems). 53BP1 foci were counted using a custom Metacyte classifier. $>2500$ nuclei were counted for each genotype (see Supplementary Table for details).

\section{PCR analysis of $V(D) J$ recombination products}

$V k_{6-23} / J k_{1}$ coding joints were amplified as previously described $[25,28] .500 \mathrm{ng}$ of genomic DNA was amplified using pkJa2 (GCCACAGACATAGACAACGGAA) and pк6d (GAAATACATCAGACCAGCATGG) primers. $2 \mu \mathrm{l}$ of this reaction was amplified using pkJa2 and pk6c (GTT GCTGTGGTTGTCTGGTG) primers. $V k_{10-95} / J k_{4}$ coding joints were amplified using JK4-pa (CGCTCAGCTTTCA CACTGACT) and V10-95-pa (TTCCTTGGTCTCCT GTTGCT) primers for the first PCR and using JK4-pb
(CAGGTTGCCAGGAATGGCTC) and V10-95-pb (TCTT GTTGACTGGCGTTTTG) primers for the second PCR. Il2 gene was amplified using IMR42 (CTAGGCCACA GAATTGAAAGATCT) and IMR43 (GTAGGTGGAA ATTCTAGCATGATGC) primers and was used as loading control.

\section{Statistical analysis}

Results are presented as mean values \pm SEM. Comparisons between groups were carried out by using a Mann-Whitney test. Statistical analyses were performed using GraphPad Prism. A $P$-value $<0.05$ was considered as statistically significant.

Acknowledgements We thank P. Moreno and M. Juan for assistance with mice. The Deriano lab members for help with pro-B-cell lines experiments. O. Fornes for cell sorting and flow cytometry assistance. The Yélamos's lab is funded by the Spanish Ministerio de Economía, Industria y Competitividad (grant SAF2017-83565-R) and The Fundación Científica de la Asociación Española Contra el Cáncer (AECC). The Deriano's lab is funded by the Institut Pasteur, the Institut National du Cancer (\# PLBIO16-181) and the European Research Council under the ERC (starting grant agreement \#310917). The Dantzer's lab is supported by LABEX ANR-10-LABX-0034_Medalis, Strasbourg University, CNRS. The Cerutti's lab is supported by the European Research Council (European Advanced Grant ERC-2011ADG-20110310) and by the Spanish Ministerio de Economía, Industria y Competitividad (grant SAF2014-52483-R). MAG-C is supported by CONACyT.

Author contributions MAG-C contributed to the generation of the mouse models and the characterization of B-cells in those animal models. MBF generated $v$ - $a b l$ pro-B-cell lines and carried out V(D)J recombination and genetic instability experiments. CL performed 53BP1 immunofluorescence experiments. FD engineered the Parp- $2^{\mathrm{f} / \mathrm{f}}$ mouse model. LM-L, JF, and CA contributed to mouse models generation and flow cytometry studies. JM-C and CM contributed to mice immunization. $\mathrm{AC}$ and PA contributed to planned and designed experiments. JY and LD planned and designed experiments and performed experiments. JY, AC, and LD wrote the manuscript. All authors discussed the results and commented on the manuscript.

\section{Compliance with ethical standards}

Conflict of interest The authors declare that they have no conflict of interest.

Publisher's note: Springer Nature remains neutral with regard to jurisdictional claims in published maps and institutional affiliations.

\section{References}

1. Hardy RR, Hayakawa K. B cell development pathways. Annu Rev Immunol. 2001;19:595-621.

2. Pillai S, Cariappa A. The follicular versus marginal zone B lymphocyte cell fate decision. Nat Rev Immunol. 2009;9:767-77.

3. Cerutti A, Cols M, Puga I. Marginal zone B cells: virtues of innate-like antibody-producing lymphocytes. Nat Rev Immunol. 2013;13:118-32. 
4. Garcia d,V, O’Leary P, Sze DM, Toellner KM, MacLennan IC. Tindependent type 2 antigens induce $\mathrm{B}$ cell proliferation in multiple splenic sites, but exponential growth is confined to extrafollicular foci. Eur J Immunol. 1999;29:1314-23.

5. Inoue T, Moran I, Shinnakasu R, Phan TG, Kurosaki T. Generation of memory B cells and their reactivation. Immunol Rev. 2018;283:138-49.

6. Tas JM, Mesin L, Pasqual G, Targ S, Jacobsen JT, Mano YM, et al. Visualizing antibody affinity maturation in germinal centers. Science. 2016;351:1048-54

7. Yelamos J, Farres J, Llacuna L, Ampurdanes C, Martin-Caballero J. PARP-1 and PARP-2: new players in tumour development. Am J Cancer Res. 2011;1:328-46.

8. Daniels CM, Ong SE, Leung AK. The promise of proteomics for the study of ADP-ribosylation. Mol Cell. 2015;58:911-24.

9. Bai P. Biology of poly(ADP-Ribose) polymerases: the factotums of cell maintenance. Mol Cell. 2015;58:947-58.

10. Menissier de MJ, Ricoul M, Tartier L, Niedergang C, Huber A, Dantzer F, et al. Functional interaction between PARP-1 and PARP-2 in chromosome stability and embryonic development in mouse. EMBO J. 2003;22:2255-63.

11. Gibson BA, Zhang Y, Jiang H, Hussey KM, Shrimp JH, Lin H, et al. Chemical genetic discovery of PARP targets reveals a role for PARP-1 in transcription elongation. Science. 2016;353:45-50.

12. Ali SO, Khan FA, Galindo-Campos MA, Yelamos J. Understanding specific functions of PARP-2: new lessons for cancer therapy. Am J Cancer Res. 2016;6:1842-63.

13. Farres J, Martin-Caballero J, Martinez C, Lozano JJ, Llacuna L, Ampurdanes $\mathrm{C}$, et al. Parp-2 is required to maintain hematopoiesis following sublethal gamma-irradiation in mice. Blood. 2013;122:44-54.

14. Farres J, Llacuna L, Martin-Caballero J, Martinez C, Lozano JJ, Ampurdanes C, et al. PARP-2 sustains erythropoiesis in mice by limiting replicative stress in erythroid progenitors. Cell Death Differ. 2015;22:1144-57.

15. Dantzer F, Mark M, Quenet D, Scherthan H, Huber A, Liebe B, et al. Poly(ADP-ribose) polymerase-2 contributes to the fidelity of male meiosis I and spermiogenesis. Proc Natl Acad Sci USA. 2006;103:14854-9.

16. Nicolas L, Martinez C, Baro C, Rodriguez M, Baroja-Mazo A, Sole F, et al. Loss of poly(ADP-ribose) polymerase-2 leads to rapid development of spontaneous T-cell lymphomas in p53deficient mice. Oncogene. 2010;29:2877-83.

17. Yelamos J, Monreal Y, Saenz L, Aguado E, Schreiber V, Mota R, et al. PARP-2 deficiency affects the survival of CD4 + CD8 + double-positive thymocytes. EMBO J. 2006;25:4350-60.

18. Navarro J, Gozalbo-Lopez B, Mendez AC, Dantzer F, Schreiber $\mathrm{V}$, Martinez C, et al. PARP-1/PARP-2 double deficiency in mouse $\mathrm{T}$ cells results in faulty immune responses and $\mathrm{T}$ lymphomas. Sci Rep. 2017;7:41962.

19. Wang ZQ, Stingl L, Morrison C, Jantsch M, Los M, SchulzeOsthoff $\mathrm{K}$, et al. PARP is important for genomic stability but dispensable in apoptosis. Genes Dev. 1997;11:2347-58.

20. Morrison C, Smith GC, Stingl L, Jackson SP, Wagner EF, Wang ZQ. Genetic interaction between PARP and DNA-PK in V(D)J recombination and tumorigenesis. Nat Genet. 1997;17:479-82.

21. Brown ML, Franco D, Burkle A, Chang Y. Role of poly(ADPribosyl)ation in DNA-PKcs- independent $\mathrm{V}(\mathrm{D}) \mathrm{J}$ recombination. Proc Natl Acad Sci USA. 2002;99:4532-7.

22. Robert I, Dantzer F, Reina-San-Martin B. Parp1 facilitates alternative NHEJ, whereas Parp2 suppresses IgH/c-myc translocations during immunoglobulin class switch recombination. J Exp Med. 2009;206:1047-56.

23. Rickert RC, Roes J, Rajewsky K. B lymphocyte-specific, Cremediated mutagenesis in mice. Nucleic Acids Res. 1997; 25:1317-8.
24. Lenden HH, Lescale C, Bianchi JJ, Yu W, Bedora-Faure M, Deriano L. Generation and CRISPR/Cas9 editing of transformed progenitor B cells as a pseudo-physiological system to study DNA repair gene function in V(D)J recombination. J Immunol Methods. 2017;451:71-77.

25. Bredemeyer AL, Sharma GG, Huang CY, Helmink BA, Walker LM, Khor KC, et al. ATM stabilizes DNA double-strand-break complexes during V(D)J recombination. Nature. 2006;442:46670.

26. Muljo SA, Schlissel MS. A small molecule Abl kinase inhibitor induces differentiation of Abelson virus-transformed pre-B cell lines. Nat Immunol. 2003;4:31-37.

27. Deriano L, Stracker TH, Baker A, Petrini JH, Roth DB. Roles for NBS1 in alternative nonhomologous end-joining of V(D)J recombination intermediates. Mol Cell. 2009;34:13-25.

28. Lescale C, Abramowski V, Bedora-Faure M, Murigneux V, Vera $\mathrm{G}$, Roth DB, et al. RAG2 and XLF/Cernunnos interplay reveals a novel role for the RAG complex in DNA repair. Nat Commun. 2016;7:10529.

29. Lescale C, Lenden HH, Blackford AN, Balmus G, Bianchi JJ, Yu $\mathrm{W}$, et al. Specific roles of XRCC4 paralogs PAXX and XLF during V(D)J recombination. Cell Rep. 2016;16:2967-79.

30. Toledo LI, Murga M, Zur R, Soria R, Rodriguez A, Martinez S, et al. A cell-based screen identifies ATR inhibitors with synthetic lethal properties for cancer-associated mutations. Nat Struct Mol Biol. 2011;18:721-7.

31. Syljuasen RG, Sorensen CS, Hansen LT, Fugger K, Lundin C, Johansson F, et al. Inhibition of human Chk1 causes increased initiation of DNA replication, phosphorylation of ATR targets, and DNA breakage. Mol Cell Biol. 2005;25:3553-62.

32. Ashworth A, Lord CJ. Synthetic lethal therapies for cancer: what's next after PARP inhibitors? Nat Rev Clin Oncol. 2018;15:564-76.

33. Hardy RR, Kincade PW, Dorshkind K. The protean nature of cells in the B lymphocyte lineage. Immunity. 2007;26:703-14.

34. Allman D, Pillai S. Peripheral B cell subsets. Curr Opin Immunol. 2008;20:149-57.

35. Ronson GE, Piberger AL, Higgs MR, Olsen AL, Stewart GS, McHugh PJ, et al. PARP1 and PARP2 stabilise replication forks at base excision repair intermediates through Fbh1-dependent Rad51 regulation. Nat Commun. 2018;9:746.

36. Hartwell LH, Szankasi P, Roberts CJ, Murray AW, Friend SH. Integrating genetic approaches into the discovery of anticancer drugs. Science. 1997;278:1064-8.

37. Thomas MD, Kremer CS, Ravichandran KS, Rajewsky K, Bender TP. c-Myb is critical for B cell development and maintenance of follicular B cells. Immunity. 2005;23:275-86.

38. Tartey S, Matsushita K, Imamura T, Wakabayashi A, Ori D, Mino $\mathrm{T}$, et al. Essential function for the nuclear protein Akirin2 in B cell activation and humoral immune responses. $\mathrm{J}$ Immunol. 2015;195:519-27.

39. Dolence JJ, Gwin KA, Shapiro MB, Hsu FC, Shapiro VS, Medina KL. Cell extrinsic alterations in splenic B cell maturation in Flt3ligand knockout mice. Immun Inflamm Dis. 2015;3:103-17.

40. Ludwig J, Federico G, Prokosch S, Kublbeck G, Schmitt S, Klevenz A, et al. Dickkopf-3 acts as a modulator of B cell fate and function. J Immunol. 2015;194:2624-34.

41. Balazs M, Martin F, Zhou T, Kearney J. Blood dendritic cells interact with splenic marginal zone $\mathrm{B}$ cells to initiate $\mathrm{T}$ independent immune responses. Immunity. 2002;17:341-52.

42. Guerra FM, Gommerman JL, Corfe SA, Paige CJ, Rottapel R. Homeodomain-interacting protein kinase (HIPK)-1 is required for splenic B cell homeostasis and optimal T-independent type 2 humoral response. PLoS ONE. 2012;7:e35533.

43. Chu H, Awasthi A, White GC, Chrzanowska-Wodnicka M, Malarkannan S. Rap1b regulates B cell development, homing, and 
T cell-dependent humoral immunity. J Immunol. 2008;181:337383.

44. de Murcia JM, Niedergang C, Trucco C, Ricoul M, Dutrillaux B, Mark M, et al. Requirement of poly(ADP-ribose) polymerase in recovery from DNA damage in mice and in cells. Proc Natl Acad Sci USA. 1997;94:7303-7.

45. Corral J, Yelamos J, Hernandez-Espinosa D, Monreal Y, Mota $\mathrm{R}$, Arcas I, et al. Role of lipopolysaccharide and cecal ligation and puncture on blood coagulation and inflammation in sensitive and resistant mice models. Am J Pathol. 2005;166:1089-98.
46. Masson M, Niedergang C, Schreiber V, Muller S, Menissier-de MJ, de Murcia G. XRCC1 is specifically associated with poly (ADP-ribose) polymerase and negatively regulates its activity following DNA damage. Mol Cell Biol. 1998;18:3563-71.

47. Rosenberg N, Baltimore D, Scher CD. In vitro transformation of lymphoid cells by Abelson murine leukemia virus. Proc Natl Acad Sci USA. 1975;72:1932-6.

48. Chaumeil J, Micsinai M, Skok JA. Combined immunofluorescence and DNA FISH on 3D-preserved interphase nuclei to study changes in 3D nuclear organization. J Vis Exp. 2013;72: e50087. 